\title{
Extremely low critical cooling rate measured on dispersed $\mathrm{Pd}_{43} \mathrm{Ni}_{10} \mathrm{Cu}_{27} \mathbf{P}_{20}$
}

\author{
Jan Schroers ${ }^{\text {a) }}$ and William L. Johnson \\ Keck Laboratory of Engineering Materials, California Institute of Technology, Pasadena, California 91125
}

(Received 5 December 2001; accepted for publication 18 January 2002)

Crystallization of dispersed $\mathrm{Pd}_{43} \mathrm{Ni}_{10} \mathrm{Cu}_{27} \mathrm{P}_{20}$ melts is studied during constant cooling and heating. Investigations are carried out on samples that are dispersed into several hundred particles which are fluxed in $\mathrm{B}_{2} \mathrm{O}_{3}$. The size of the particles is chosen in such a way that crystallization of individual particles can be observed. Constant cooling experiments with rates between 0.3 and $0.0016 \mathrm{~K} / \mathrm{s}$ are performed. In order to determine the fraction of particles that crystallize upon cooling, the crystallization during subsequent heating at $0.3 \mathrm{~K} / \mathrm{s}$ is utilized. $10 \%-15 \%$ of the particles do not crystallize during cooling with a rate as low as $0.005 \mathrm{~K} / \mathrm{s}$. This is the lowest rate that avoids crystallization ever measured for a metallic system. This extremely low critical cooling rate suggests that a fraction of the particles do not contain the impurities that act as nuclei in bulk samples. Therefore, in these particles, nuclei first have to form and crystallization does not take place, as it was found for bulk $\mathrm{Pd}_{43} \mathrm{Ni}_{10} \mathrm{Cu}_{27} \mathrm{P}_{20}$, by the growth on pre-existing nuclei formed by impurities. (C) 2002 American Institute of Physics. [DOI: 10.1063/1.1462861]

$\mathrm{Pd}_{40} \mathrm{Ni}_{40} \mathrm{P}_{20}$ is the first bulk metallic glass (BMG), discovered in 1974 by Chen. ${ }^{1}$ It was found that the glass forming ability (GFA) can be improved by fluxing this alloy in $\mathrm{B}_{2} \mathrm{O}_{3} .{ }^{2}$ A critical cooling rate as low as $1 \mathrm{~K} / \mathrm{s}$ was measured. By partially replacing $\mathrm{Ni}$ with $\mathrm{Cu}$ in $\mathrm{Pd}_{40} \mathrm{Ni}_{40} \mathrm{P}_{20}$, an alloy with a substantially better GFA, $\mathrm{Pd}_{40} \mathrm{Ni}_{10} \mathrm{Cu}_{30} \mathrm{P}_{20}$ was found. ${ }^{3}$ The GFA could be even further improved by adjusting the $\mathrm{Pd}$ composition with respect to $\mathrm{Cu}^{4}{ }^{4}$ This resulted in the $\mathrm{Pd}_{43} \mathrm{Ni}_{10} \mathrm{Cu}_{27} \mathrm{P}_{20}$ alloy, which has the lowest critical cooling rate of all BMG's discovered so far. The fact that the GFA can be improved by fluxing in $\mathrm{B}_{2} \mathrm{O}_{3}$ suggests a heterogeneous nucleation mechanism. Indeed, it was concluded in several investigations that the major practical obstacle to glass formation in Pd-based systems is heterogeneous nucleation. ${ }^{5-7}$ In a recent publication, it was observed that the crystallization mechanism for $\mathrm{Pd}_{43} \mathrm{Ni}_{10} \mathrm{Cu}_{27} \mathrm{P}_{20}$ changes from a nucleation-controlled mechanism at high temperatures to a growth-controlled mechanism at low temperatures. ${ }^{8}$ The temperature of this transition could be influenced by heterogeneities. ${ }^{7}$ This suggests that at the transition from nucleation- to growth-controlled crystallization, the critical cluster size reaches the effective size of the impurities and they thereby act as stable nuclei. Therefore, crystallization in the growth-controlled region proceeds by the growth of pre-existing nuclei which are the impurities.

Statistical methods are a powerful tool to investigate the crystallization of supercooled liquids. ${ }^{9-11}$ One approach is to disperse the sample into small particles. It was found that much deeper undercoolings can be achieved in samples consisting of a large number of small isolated droplets than in one large sample. By dividing the sample into small particles, the probability increases that some do not contain impurities, wherefore heterogeneous nucleation is avoided and they can nucleate in a homogeneous manner. It should be mentioned that the only cases where homogeneous nucleation has been observed involved samples that were also di-

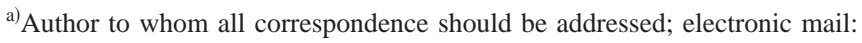
schroers@hyperfine.caltech.edu
}

vided into many particles. ${ }^{10,12}$ However, those studies were limited to an undercooling region that is far above the nose temperature in the time-temperature-transformation (TTT) diagram. ${ }^{10,11}$ Recently, $\mathrm{Pd}_{43} \mathrm{Ni}_{10} \mathrm{Cu}_{27} \mathrm{P}_{20}$ samples were divided into small particles, each of a size for which crystallization of each individual particle could still be observed. ${ }^{8}$ These studies were performed in the entire undercooled liquid region and reveal an inside view in the crystallization mechanism that changes from a nucleation-controlled crystallization at high temperatures to a growth-controlled crystallization at low temperatures.

This letter reports on crystallization studies during constant cooling and heating of $\mathrm{Pd}_{43} \mathrm{Ni}_{10} \mathrm{Cu}_{27} \mathrm{P}_{20}$ to determine the critical cooling rate. A dispersion technique is applied where the sample is divided into several hundred particles that are processed simultaneously. For the size of the particles, the purity of the material suggests that some of the particles should be free of impurities and subsequently crystallize in a different manner.

The following high purity ingot material was used to prepare the alloy: Pd, 3-6 mm pieces, Cerac Incorporated, 99.95\%; Ni, rod, Alfa Aesar, 99.999\%; Cu, shots, Alfa Aesar, 99.9999\%; P, lump, 99.999+\%. $\mathrm{Pd}, \mathrm{Ni}$, and $\mathrm{Cu}$ were prealloyed by inductive melting in a quartz tube. Amorphous samples were prepared by inductively melting the prealloyed $\mathrm{PdNiCu}$ and the phosphorus in quartz tubes for 20 min at $1200 \mathrm{~K}$ followed by water quenching. During this procedure, the samples were fluxed in $\mathrm{B}_{2} \mathrm{O}_{3}$. Constant cooling and heating experiments were carried out in a PerkinElmer differential scanning calorimetry (DSC) 7 analyzer. A dispersed sample consists of several hundred particles of diameters between 100 and $300 \mu \mathrm{m}$, processed in graphite crucibles with a mixture of $\mathrm{B}_{2} \mathrm{O}_{3}$ and $\mathrm{Al}_{2} \mathrm{O}_{3}$ particles. The $\mathrm{Al}_{2} \mathrm{O}_{3}$ particles, about $50 \mu \mathrm{m}$ in size, were used to avoid fusing of the liquid particles during processing.

Prior to the cooling experiment, the dispersed sample was held for $120 \mathrm{~s}$ at $990 \mathrm{~K}$. From this temperature, the sample was cooled with various constant cooling rates below its glass transition temperature. The DSC thermograms measured upon cooling are shown in Fig. 1. They are depicted 

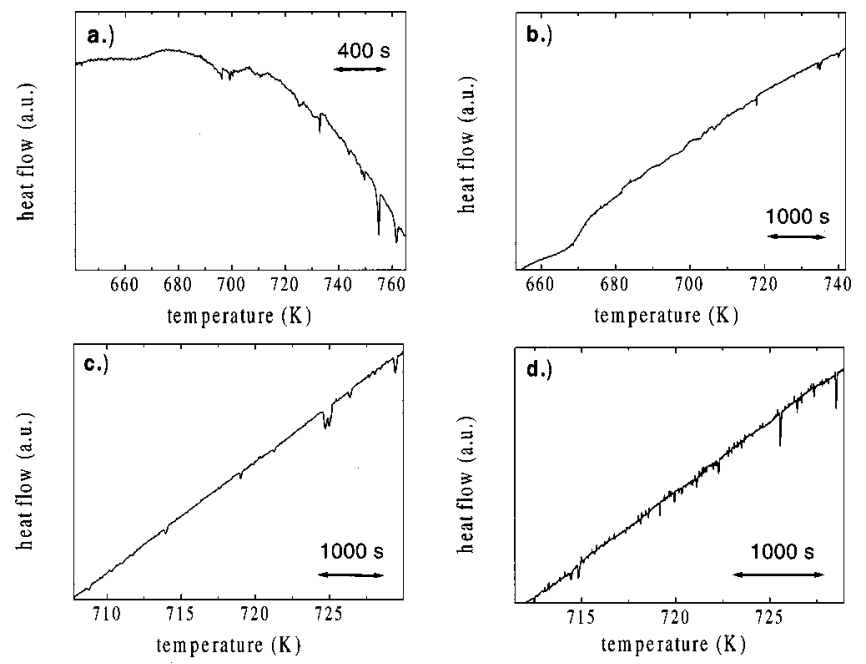

FIG. 1. Thermograms of constant cooling experiments with different rates: (a) $0.05 \mathrm{~K} / \mathrm{s}$, (b) $0.016 \mathrm{~K} / \mathrm{s}$, (c) $0.005 \mathrm{~K} / \mathrm{s}$, and (d) $0.0016 \mathrm{~K} / \mathrm{s}$. Note that the $x$ and $y$ scales vary for the different cooling rates. The different time scales are indicated.

for cooling rates of $0.05 \mathrm{~K} / \mathrm{s}$ [Fig. 1(a)], $0.016 \mathrm{~K} / \mathrm{s}$ [Fig. 1(b)], $0.005 \mathrm{~K} / \mathrm{s}$ [Fig. 1(c)], and $0.0016 \mathrm{~K} / \mathrm{s}$ [Fig. 1(d)]. For temperatures above $700 \mathrm{~K}$, the peaks in the thermograms represent the crystallization of individual particles. Below this temperature, crystallization events overlap. This is caused by the broadening of the crystallization peak at lower temperatures due to the decrease of the growth rate and by an increase of the overall crystallization rate of all particles. With decreasing temperature, the crystallization peaks broaden. Note that the $x$ and $y$ scale are different for each of the various cooling rates in Fig. 1. A slower cooling also makes the crystallization events on this plot appear narrower. Therefore, the different time scales are depicted in Fig. 1.

The subsequent heating with $0.3 \mathrm{~K} / \mathrm{s}$ was used to determine the fraction of particles that crystallized upon cooling with different rates. The corresponding DSC thermograms are shown in Fig. 2. Onset and end of crystallization and the heat of crystallization measured on samples processed under different cooling histories are summarized in Table I. A sample that was cooled with $0.05 \mathrm{~K} / \mathrm{s}$ [Fig. 2(a)] crystallizes at $694 \mathrm{~K}$ and releases $31.6 \mathrm{~J} / \mathrm{g}$. Cooling a sample with 3.3 $\mathrm{K} / \mathrm{s}$, where no crystallization was observed upon cooling, results in a heat release during subsequent heating of 54.7 $\mathrm{J} / \mathrm{g}$. By comparing the heat releases of the differently processed samples, we can conclude that $40 \%$ of the particles crystallize during cooling at $0.05 \mathrm{~K} / \mathrm{s}$. For comparison, a bulk sample of $2.2 \times 10^{-2} \mathrm{~g}$ that was cooled with $3.3 \mathrm{~K} / \mathrm{s}$ was also heated with $0.03 \mathrm{~K} / \mathrm{s}$. The main difference in the crystallization during subsequent heating of a bulk and a dispersed sample cooled with the same rate of $3.3 \mathrm{~K} / \mathrm{s}$ is that the bulk sample exhibits a narrower crystallization peak than a dispersed sample. The dispersed sample cooled with 0.016 K/s [Fig. 2(b)] shows a slightly higher onset of crystallization and the peak broadens by about $20 \mathrm{~K}$. From the heat release of $6 \mathrm{~J} / \mathrm{g}$, we can conclude that between $10 \%-15 \%$ of the particles did not crystallize upon cooling. Even for a dispersed sample that was cooled with $0.005 \mathrm{~K} / \mathrm{s}$ [Fig. 2(c)], $10 \%-15 \%$ of the particles did not crystallize upon cooling, reflected in the heat release of $6 \mathrm{~J} / \mathrm{g}$ measured upon subseDownloaded 17 Aug 2007 to 131.215.225.175. Redistribution subject
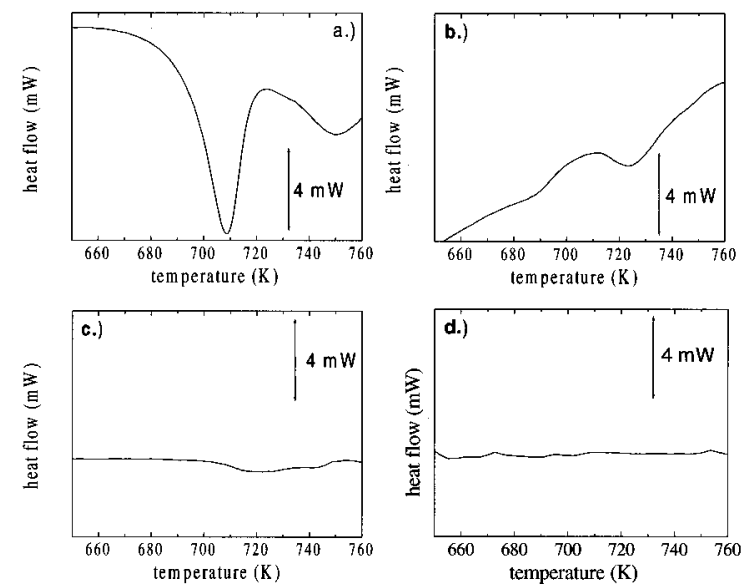

FIG. 2. DSC thermograms of $0.3 \mathrm{~K} / \mathrm{s}$ heating experiments, performed on samples that were cooled with different rates. (a) $0.05 \mathrm{~K} / \mathrm{s}$, (b) $0.016 \mathrm{~K} / \mathrm{s}$, (c) $0.005 \mathrm{~K} / \mathrm{s}$, and (d) $0.0016 \mathrm{~K} / \mathrm{s}$. Cooling with $0.05 \mathrm{~K} / \mathrm{s}, 0.016 \mathrm{~K} / \mathrm{s}$, and 0.005 $\mathrm{K} / \mathrm{s}$ is sufficient for a fraction of the particles to avoid crystallization.

quent heating. Cooling with $0.0016 \mathrm{~K} / \mathrm{s}$ [Fig. 2(d)] results in the crystallization of all particles during cooling as evidenced by no heat release on subsequent heating.

The cooling experiments have shown that the various particles have different critical cooling rates, $R_{c}$. Whereas none of the particles crystallize upon cooling with $3.3 \mathrm{~K} / \mathrm{s}$, about $40 \%$ crystallize during cooling with $0.05 \mathrm{~K} / \mathrm{s}$. For even slower rates of 0.016 and $0.005 \mathrm{~K} / \mathrm{s}$, between $10 \%$ and $15 \%$ of the particles still did not crystallize during cooling. By dividing the sample into small particles, the nucleation rate, assuming bulk nucleation, in each of the particles is much smaller than in the bulk sample and can be described by $I_{s s}$ (bulk) $=\Sigma I_{s s}$ (particles). Kelton already pointed out that if comparing undercooling results, the sample size has to be taken into account since the nucleation rate is an extensive quantity. ${ }^{13}$ One could argue that the lower nucleation rate in the individual particles causes the lower $R_{c}$ of some of the particles in the dispersed sample. This, however, would only hold true if nucleation is the limiting step for glass formation, which would be the case if the growth velocity is sufficiently large that the time scale for crystallization is dominated by the time required to form nuclei. In $\mathrm{Pd}_{43} \mathrm{Ni}_{10} \mathrm{Cu}_{27} \mathrm{P}_{20}$, the limiting step for glass formation is the growth of pre-existing nuclei. Each nucleus grows to a size which is on the order of magnitude of the size of the particles. In other words, the crystallization rate of a bulk sample would be comparable to the crystallization rate of a dispersed sample if each particle contains impurities. A decrease of $R_{c}$ simply by decreasing the particle size and not by gaining some particles that do not contain impurities would be observable if the particle size is substantially smaller than the crystal size in the bulk sample. Therefore, the finding that some particles did not crystallize even with the low rate of $0.005 \mathrm{~K} / \mathrm{s}$ suggests different crystallization mechanisms in the various particles. Critical cooling rates measured on bulk $\mathrm{Pd}_{43} \mathrm{Ni}_{10} \mathrm{Cu}_{27} \mathrm{P}_{20}$ samples vary depending on the flux treatment and the purity of the alloy. For low purity $\mathrm{Pd}_{43} \mathrm{Ni}_{10} \mathrm{Cu}_{27} \mathrm{P}_{20}$, a critical cooling rate of $0.4 \mathrm{~K} / \mathrm{s}$ was measured and $R_{c}=0.09 \mathrm{~K} / \mathrm{s}$ if processed in $\mathrm{B}_{2} \mathrm{O}_{3} .{ }^{14}$ The high purity material exhibits a slightly lower $R_{c}$ of $0.07 \mathrm{~K} / \mathrm{s}$ if processed in $\mathrm{B}_{2} \mathrm{O}_{3}{ }^{7}$ The number density of nuclei was to AlP license or copyright, see http://apl.aip.org/apl/copyright.jsp 
TABLE I. Onset and end temperatures of the crystallization peak measured upon subsequent heating with 0.3 $\mathrm{K} / \mathrm{s}$ on dispersed $\mathrm{Pd}_{43} \mathrm{Ni}_{10} \mathrm{Cu}_{27} \mathrm{P}_{20}$ samples cooled with various rates. The heat release measured during subsequent heating is utilized to determine the volume fraction crystallized upon cooling.

\begin{tabular}{ccccc}
\hline \hline Cooling rate $(\mathrm{K} / \mathrm{s})$ & $\mathrm{T}_{x}$ onset $(\mathrm{K})$ & $\mathrm{T}_{x}$ end $(\mathrm{K})$ & $\Delta \mathrm{H}(\mathrm{J} / \mathrm{g})$ & $\begin{array}{c}\text { Percentage crystallized } \\
\text { during cooling }(\%)\end{array}$ \\
\hline $3.3^{\mathrm{a}}$ & 694 & 705 & 53.3 & 0 \\
3.3 & 698 & 718 & 54.7 & 0 \\
0.05 & 694 & 717 & 31.6 & 40 \\
0.016 & 708 & 736 & 6 & $85-90$ \\
0.005 & 703 & 739 & 6 & 100 \\
0.0016 & $\cdots$ & $\cdots$ & 0 & 90 \\
\hline \hline
\end{tabular}

${ }^{\mathrm{a} B u l k}$ sample of $2.2 \times 10^{-2} \mathrm{~g}$.

estimated from the microstructure of a bulk $\mathrm{Pd}_{43} \mathrm{Ni}_{10} \mathrm{Cu}_{27} \mathrm{P}_{20}$ sample that crystallized at low temperatures below the nose in the time temperature-transformation diagram. It was found to be $\sim 10^{14}$ nuclei $/ \mathrm{m}^{3}$ for a sample prepared from low purity material and $\sim 10^{10}$ nuclei $/ \mathrm{m}^{3}$ for a high purity sample. ${ }^{7}$ This finding suggests that the impurities act as nuclei. Comparing the average volume of an impurity of $\sim 10^{-10} \mathrm{~m}^{3}$ with the average size of a particle of 5 $\times 10^{-12} \mathrm{~m}^{3}$ results in about $5 \%$ of the particles that still contain impurities. This should be considered as a rough order of magnitude estimate since the impurity density was estimated indirectly from a microstructure and the size distribution (100-300 $\mu \mathrm{m})$ was not considered. The estimate, however, suggests that dividing the sample into particles with diameters of about $200 \mu \mathrm{m}$ should result in a considerable fraction of particles that do not contain any impurities.

It was found in isothermal experiments that for temperatures above the nose in the TTT diagram, the time to reach crystallization scatters enormously. ${ }^{8,15,16}$ By cooling the dispersed sample, it first has to pass the high temperature region where crystallization is nucleation controlled. In this region, it was observed that the purity of the material, i.e., whether or not a particle contains impurities, does not substantially alter the nucleation probability. ${ }^{7}$ Therefore, particles with and without impurities pass this region with a similar probability. The stochastical nature of the crystallization process in this temperature region explains why some particles crystallize upon cooling through this temperature region, whereas others remain liquid. The fraction of particles that crystallize in this nucleation-controlled region simply depends on the cooling rate. Below a certain temperature, a drastic decrease of the scatter was observed. In this temperature region, it was found that impurities strongly influence the crystallization behavior. ${ }^{7}$ The temperature at which the scatter vanishes as well as the position of the nose in the TTT diagram are influenced by the purity of the material. It was suggested that the impurities act as nuclei below this transition temperature by the fact that the critical cluster radius drops below the effective size of the impurities. ${ }^{7}$ In this temperature region, crystallization proceeds by crystalline growth on the impurities. This causes particles containing impurities to crystallize spontaneously below this temperature. Particles without these impurities follow a different crystallization mechanism. They first have to form nuclei which is time consuming. Whether or not this proceeds in a homogenous way cannot be unambiguously concluded from the results. Although the growth of pre-existing nuclei is the dominating crystallization mechanism that limits the glass formation, minor surface crystallization was also observed. ${ }^{7}$ This surface crystallization, observed on bulk samples does become more important at smaller particle sizes.

$\mathrm{Pd}_{43} \mathrm{Ni}_{10} \mathrm{Cu}_{27} \mathrm{P}_{20}$ samples were dispersed into several hundred particles, and their crystallization was investigated during constant heating and cooling. Upon cooling, the crystallization of individual particles can be detected. Cooling with a rate as low as $0.005 \mathrm{~K} / \mathrm{s}$ still avoids crystallization of approximately $10 \%-15 \%$ of the particles. This is the lowest critical cooling rate measured for a metallic system. The drastic decrease in the critical cooling rate compared to the bulk samples is explained by the fact that in the bulk samples, the limiting step to glass formation is the growth of pre-existing nuclei. The results suggest that some of the particles in the dispersed sample do not contain the impurities which cause crystallization in the bulk material by acting as pre-existing nuclei. Whether the corresponding nucleation rate follows a homogeneous mechanism cannot be unambiguously concluded from the experimental results.

This work was supported by the National Aeronautics and Space Administration (Grant No. NAG8-1744) and the Department of Energy (Grant No. DEFG03086ER45242). The authors express their gratitude to Natassia Gaznick for technical assistance.

${ }^{1}$ H. S. Chen, Acta Metall. 22, 1505 (1974).

${ }^{2}$ H. W. Kui, A. L. Greer, and D. Turnbull, Appl. Phys. Lett. 45, 615 (1984).

${ }^{3}$ N. Nishiyama and A. Inoue, Mater. Trans., JIM 37, 1531 (1996).

${ }^{4}$ I.-R. Lu, G. Wilde, G. P. Görler, and R. Willnecker, J. Non-Cryst. Solids 250, 577 (1999).

${ }^{5}$ A. J. Drehman and A. L Greer, Acta Metall. 32, 323 (1984).

${ }^{6}$ N. Nishiyama and A. Inoue, Acta Mater. 47, 1487 (1999).

${ }^{7}$ J. Schroers, Y. Wu, and W. L. Johnson, Philos. Mag. A 82, 1207 (2002).

${ }^{8}$ J. Schroers, R. Busch, Y. Wu, and W. L. Johnson, Acta Mater. 49, 2773 (2001).

${ }^{9}$ B. Vonnegut, J. Colloid Sci. 3, 563 (1948).

${ }^{10}$ D. Turnbull, J. Chem. Phys. 20, 411 (1952).

${ }^{11}$ J. H. Perepezko and J. S. Paik, J. Non-Cryst. Solids 61, 113 (1984).

${ }^{12}$ J. H. Perepezko, Mater. Sci. Eng. 65, 125 (1984).

${ }^{13}$ K. F. Kelton, Solid State Phys. 45, 75 (1991).

${ }^{14}$ J. Schroers, R. Busch, and W. L. Johnson, Appl. Phys. Lett. 77, 1158 (2000).

${ }^{15}$ J. Schroers, R. Busch, and W. L. Johnson, Appl. Phys. Lett. 76, 2343 (2000).

${ }^{16}$ J. Schroers and W. L. Johnson, Mater. Trans., JIM 41, 1530 (2000). 